\title{
The Effect of Hangul Font on Reading Speed in the Computer Environment
}

\author{
Sunkyoung Kim, Ko Eun Lee, Hye-Won Lee \\ Department of Psychology, Ewha Womans University, Seoul, 120-750
}

\begin{abstract}
Objective: The aim of this study is to investigate the effect of Hangul font on reading speed when texts are displayed on the computer screen. Background: Reading performance is influenced by fonts. However, there are few studies of Hangul font from a cognitive perspective. Fonts could affect reading performance directly and indirectly, interacting with other visual-perceptual factors such as size, word spacing, and line spacing. Method: In experiment 1, two variables were manipulated; a frame condition(square frame · non-square frame) and a stroke condition(serif · sans-serif). According to each condition, one of the four fonts was applied to the texts. The height of the four fonts was controlled. The participants were asked to read aloud the presented texts. In experiment 2, the non-square frame fonts were adjusted to have approximately the same size, width, letter spacing, and word spacing as the square frame fonts. The experimental design and task used in experiment 2 were identical with experiment 1. Results: In general, reading speed was faster in the square frame fonts than in the non-square frame fonts. The reading speed was not significantly different across stroke conditions. Conclusion: The frame of Hangul font significantly influenced reading speed. These results suggest that the type of Hangul font is a factor to affect reading performance. Application: The frame of fonts should be considered in designing of new fonts. The square frame fonts should be the preferred choice to enhance legibility.
\end{abstract}

Keywords: Hangul, Font, Reading, Legibility, Readability

\section{Introduction}

읽기(reading)는 입력된 언어 자극을 글자, 단어, 문장 수 준에서 복합적으로 처리하는 고차원적 인지 활동이며, 기본 적으로 시각적 정보처리 과정이다. 따라서 읽기의 총체적 활 동을 설명하기 위해서는 먼저 읽기 자료의 시지각적 요인들 이 읽기 수행에 미치는 영향을 확인해야 한다. 지금까지 읽기 에 영향을 미치는 요소들로 글자 크기(Legge and Bigelow, 2011), 글자 간격(Yu et al., 2007), 대비(Legge et al., 1987 등과 관련한 연구들이 이루어졌으나, 글자체에 대한
연구는 상대적으로 적다. 특히 인지심리학적 관점에서 한글 글자체를 조사한 연구는 드물다. 글자체는 읽기 수행에 직접 적 영향을 미칠 뿐만 아니라, 글자 크기, 글자 간격, 글줄 간격 등 다른 시지각적 요인들과 함께 상호작용하기 때문에 읽기에서 중요한 요소라고 할 수 있다(Lee et al., 1993; Russell-Minda et al., 2007). 따라서 체계적으로 한글 글 자체를 구분하여 각각의 시지각적 속성을 밝혀내고 그것이 읽기에 미치는 영향에 대해 연구할 필요가 있다.

한글은 자음과 모음 또는 초성 - 중성 - 종성이 결합되어 음절 단위로 처리되기 때문에 (Park, 2006), 한글 글자체 연 구에서는 음절을 둘러싼 틀 모양에 따라 네모틀 글자체와

Corresponding Author: Hye-Won Lee. Department of Psychology, Ewha Womans University, Seoul, 120-750.

Phone: +82-2-3277-4103, E-mail: hwlee@ewha.ac.kr

Copyright@2013 by Ergonomics Society of Korea(pISSN:1229-1684 eISSN:2093-8462). All right reserved.

(c) This is an open-access article distributed under the terms of the Creative Commons Attribution Non-Commercial License(http://creativecommons.org/licenses/by-nc/3.0/), which permits unrestricted non-commercial use, distribution, and reproduction in any medium, provided the original work is properly cited. http://www.esk.or.kr 
탈네모틀 글자체로 구분하여 비교한 연구가 대부분이다 (Jung et al., 1993; Kim and Cheong, 1992; Lee et al., 1993). 네모틀 글자체는 '가', '고', '과', '각', '곡', '곽'으로 구분 되는 여섯 가지 한글 글자 유형에 상관없이 글자를 둘러싼 사각틀이 고정되어 있어서 글자 모양은 정형적이지만, 틀에 맞게 자모의 상대적 위치 및 모양은 달라지는 글자체다. 대 표적인 예로 바탕체, 돋움체, 굴림체를 들 수 있다. 반면 탈 네모틀 글자체는 글자 유형에 따라 사각 틀이 달라지기 때 문에 글자 모양은 비정형적이지만, 자모 모양은 항상 일정하 거나 변화가 적은 글자체다(Jung et al., 1993). 대표적인 예 로는 휴먼샘체, 휴먼아미체, 안상수체 등이 있다(Figure 1).

\section{네모틀 글자체 바탕체 돋움체 굴림체 탈네모틀 글자체 유멘샘체 휴맨아미체 아상ㅅㅅㅊㅊㅔ}

Figure 1. Square frame fonts and non-square frame fonts

실생활에서는 탈네모틀 글자체보다 네모틀 글자체가 주로 사용되고 있다. 인쇄 매체에서는 바탕체와 신명조체가 가 장 많이 사용되고 있는데, 두 글자체 모두 네모틀 글자체에 해당된다. 검색포탈, 언론사, 종합쇼핑몰, 정부기관 사이트 20 개를 분석한 결과, 인터넷에서 가장 많이 사용되는 글 자체도 네모틀 글자체인 굴림체와 돋움체였다. 구체적으로 $90 \%$ 의 검색포탈과 언론사는 본문용 글자체로 굴림체를 채 택하고 있었고, $90 \%$ 의 종합쇼핑몰과 정부기관은 돋움체를 채택하고 있었다.

네모틀 글자체와 탈네모틀 글자체에서의 읽기 수행을 비 교하였을 때 탈네모틀 글자체보다 네모틀 글자체에서 읽기 수행이 향상되는 것으로 나타났다. 명명 과제를 사용한 Kim 과 Cheong (1992)의 연구에서는 단어의 음절 수에 상관없 이 탈네모틀 글자체인 샘물체보다 네모틀 글자체인 명조체 에서 유의미하게 더 정확한 수행이 나타났다. 읽기 과제에서 도 탈네모틀 글자체(샘물체, 한체)보다 네모틀 글자체 (명 조체, 고딕체)에서 더 우월한 수행을 보였다(Jung et al., 1993). 100글자 읽기에 소요된 평균 시간은 탈네모틀 글 자체보다 네모틀 글자체에서 0.33 초 더 빠르게 나타났다 (9.77초 대 9.44초). 네모틀 글자체에서 읽기 속도가 향상 되는 결과는 글줄 간격을 $2 \mathrm{~mm}$ (좁음), $5 \mathrm{~mm}$ (보통), $8 \mathrm{~mm}$ (넓음)로 조정하거나, 글자의 가로 대 세로 비율이 1 대 1 인 장평률 $100 \%$ 를 50\%, 150\%, 200\%로 조정하여도 유지되 었다(Jung et al., 1993; Lee et al., 1993). 그러나 세 연구 에서의 자극 제시 환경은 현재 상용되는 컴퓨터 환경과는
차이가 있었다. Kim과 Cheong(1992)에서는 인쇄 후 슬라 이드를 제작하여 환등기로 제시하였다. Jung 등(1993), Lee 등(1993)은 컴퓨터 화면에서 자극을 제시하였으나 인쇄 후 그림 파일로 변환한 자극을 사용하여 실제 컴퓨터 화면에서 글을 읽을 때와는 해상도가 다르게 나타났다.

2001년 이후부터는 네모틀 글자체보다 탈네모틀 글자체 나 네모틀 및 탈네모틀 특성을 혼합한 글자체의 개발이 주 를 이루고 있다(Kim and Kim, 2005). 글자체 한 벌을 제 작하기 위해 필요한 글자 수가 탈네모틀 글자체에서 $1 / 40$ 정도로 더 적어 제작 면에서 경제적이기 때문이다(네모틀 글자체 2,350자, 탈네모틀 글자체 67자, $\mathrm{Yu}, 2006)$. 가독 성 측면에서도 네모틀 글자체가 탈네모틀 글자체에 비해 비 효율적이라는 주장이 제기되었다. 네모틀 글자체는 사각틀에 맞추어 글자가 제시되기 때문에 글자의 유형에 따라 균형점 이 계속 변하게 된다(Yu, 2006). 이로 인해 가로 글줄이 정 리되어 보이지 않고 글자 간 간격이 고르게 보이지 않아 읽 기에 어려움을 줄 수 있다고 제안되었다(Yoo, 2010). 그러 나 이러한 주장에 대해 상용하는 컴퓨터 환경에서 실질적으 로 검증한 연구는 아직까지 없었다.

틀 외에도 읽기 수행에 영향을 미치는 글자체 요소로 획 의 모양이 있다(Moret-Tatay and Perea, 2011). 글자체 는 획의 모양에 따라 크게 세리프체(serif)와 산세리프체 (sans-serif)로 구분할 수 있다. 세리프체는 획의 굵기가 균일하지 않고, 획의 가장자리가 꺾임과 장식으로 강조되어 있으며, 서양의 펜글씨에서 유래한 것이다. 마찬가지로 세리 프체 특성을 갖는 한글 글자체들은 붓글씨에서 유래하였다 (Min, 2011). 대표적인 예로는 Times New Roman, 바탕 체, 궁서체 등을 들 수 있다. 산세리프체는 글자 획이 비교 적 일관적이고, 꺾임과 장식으로 강조되지 않는다(Choi and Yoon, 2007). 산세리프체의 예로는 Arial, Verdana, 돋움체, 굴림체 등이 있다(Figure 2).

\section{세리프체 Times New Roman 바탕체 궁서체 산세리프체 Arial Verdana 돋움체 굴림체}

Figure 2. Serif fonts and sans-serif fonts

타자기 및 컴퓨터가 개발되기 전부터 펜과 붓은 널리 사용 되어 왔고, 지금까지도 출판본의 대부분이 세리프체를 채택 하고 있기 때문에(Moret-Tatay and Perea, 2011), 산세리 프체보다는 세리프체가 사람들에게 더 친숙할 수 있다. 또한 세리프체에서 나타나는 획의 굵기 변화, 꺾임과 장식 등이 철자를 더 고유하게 만들고, 철자 획의 위치에 대한 단서를 
제공해 주어서 산세리프체보다 세리프체가 단어 재인을 촉 진시킨다는 주장도 제기되었다(McLean, 1980; Rubinstein, 1998: Moret-Tatay and Perea, 2011에서 재인용). 그러 나 인쇄 매체 환경에서 세리프체와 산세리프체 간 읽기 수 행을 비교한 연구들에서는 결과가 혼재되어 있다. 세리프를 추가하는 것이 철자 변별에 도움을 준다는 연구 결과도 존 재하지만(MacKeben, 2000), 산세리프체에서의 읽기 속도 가 더 빠르게 나타났다는 연구 결과도 있다(Perera, 2001; Russell-Minda et al., 2007에서 재인용). 대부분의 연구에 서는 두 글자체 간에 유의미한 읽기 수행 차이가 나타나지 않았다(Akhmadeeva et al., 2012; Arditi and Cho, 2005; Smither and Braun, 1994).

반면 컴퓨터 환경에서는 산세리프체에서 수행이 향상된다 는 결과들이 비교적 일관적으로 보고되었다. 어휘 판단 과 제에서 14 포인트로 자극을 제시했을 때 세리프체보다 산세 리프체 자극에 대한 반응 시간이 약 $19 \mathrm{~ms}$ 빠르게 나타났다 (Moret-Tatay and Perea, 2011). 신속 순차 제시(Rapid Serial Visual Presentation: RSVP) 방법을 사용하여 문장 을 제시하였을 때도, 글자 높이가 $8 \mathrm{~mm}$ (보는 거리 $100 \mathrm{~cm}$ ) 일 때 세리프체보다 산세리프체에서 약 $11.5 \%$ 빠른 읽기 속도가 나타났고(Yager et al., 1998), 글자 크기 4포인트 (보는 거리 $40 \mathrm{~cm}$ ) 일 때 세리프체보다 산세리프체에서 약 $20 \%$ 빠른 읽기 속도가 나타났다(Morris et al., 2002). 6명 의 참가자만을 대상으로 하여 유의하지는 않았지만, 자연스 런 읽기 상황에서도 세리프체로 제시할 때보다 산세리프체로 제시할 때 읽기 속도가 더 빠르게 나타났고 더 적은 안구 회귀(regression)를 보이는 패턴이 관찰되었다(Josephson, 2008).

세리프체와 산세리프체 간 수행 차이는 컴퓨터 환경에서 글자가 충분히 큰 크기로 제시되면 감소하기도 한다. 글자 크기가 16 포인트일 경우 세리프체와 산세리프체 간 읽기 속 도 차이가 거의 나타나지 않았다(Morris et al., 2002). 참가 자 별로 글자 크기와 보는 거리를 조정하여 최대 읽기 수행 을 위한 환경을 제공하였을 때에도 $0 \%, 5 \%, 10 \%$ 로 세리프 체의 요소를 더하는 것이 읽기 속도에서의 유의한 차이를 가져오지 않았다(Arditi and Cho, 2005). 이와 같은 결과는 컴퓨터 화면에서의 해상도 한계로 특히 글자 크기가 작아질 때 세리프체의 장식 요소가 시각적 노이즈로 작용하기 때문 으로 설명되었다. 글자 크기가 작을 경우 세리프체의 장식 요소가 명확하게 표현되지 않아 획이 번져 보이거나 겹쳐 보 임으로써 글자 재인을 방해할 수 있다. 그러나 글자 크기가 일정 크기 이상으로 커지면 세리프체의 장식 요소가 명확 히 표현될 수 있다(Josephson, 2008; Moret-Tatay and Perea, 2011; Morris et al., 2002).

최근에는 디지털 기기를 통한 읽기 활동이 증가하고 있으
므로 컴퓨터 환경에서 글자체의 틀(네모틀 및 탈네모틀) 과 획(세리프 및 산세리프)의 영향을 체계적으로 살펴보아야 할 필요성이 있다. 본 연구에서는 다음과 같은 사항을 알아 보고자 한다. 첫째, 탈네모틀 글자체보다 네모틀 글자체에서 읽기 속도가 향상되는지 알아볼 것이다. 지금까지 국내 선행 연구들에서 탈네모틀 글자체보다 네모틀 글자체에서 더 빠 른 읽기 속도가 보고되었지만, 이 연구들에서는 상용되는 컴 퓨터 환경의 특성이 제대로 반영되지 못했다. 또한 디자인 측면에서는 탈네모틀 글자체가 우월하다는 주장이 제기되고 있는데, 실제 컴퓨터 환경에서의 읽기 수행에서 탈네모틀 글 자체가 네모틀 글자체에 비해 더 수행을 향상시키는지 확인 해야 할 필요가 있다.

둘째, 세리프체보다 산세리프체에서 읽기 속도가 향상되는 지 알아볼 것이다. 획의 모양이 읽기에 미치는 영향은 주로 서양의 알파벳을 기준으로 조사되었으나, 획의 모양은 한글 에도 적용할 수 있는 글자체 요소이다. 영어권 연구들은 컴 퓨터 환경에서 세리프가 시각적 노이즈로 작용하여 읽기 수 행을 방해함을 보여주었다. 영어와 표기 체계가 다른 한글에 서는 모아쓰기로 인해 인접 자모가 측면뿐 아니라 상하로도 위치하게 된다. 이 경우 세리프의 장식 요소가 시각적인 노 이즈로 작용하는 범위가 커져 영어에 비해 한글 세리프체에 서의 수행이 더 악화될 가능성이 있다.

셋째, 탈네모틀 글자체에서 세리프의 효과가 더 크게 나타 나는지 살펴보고자 한다. 탈네모틀 글자체일 때는 받침이 없 을 때 글자 크기가 $1 / 2$ 로 감소할 뿐 아니라, 장평과 자간이 네모틀에 비해 좁아 글자가 표현되는 공간이 상대적으로 작 아진다. 이러한 조건에서는 세리프의 장식 요소가 노이즈로 더 크게 작용하여 읽기 속도가 보다 급격히 저하될 수 있다 (Moret-Tatay and Perea, 2011; Woods et al., 2005).

\section{Method}

\subsection{Experiment 1}

실험 1에서는 두 가지 변인이 조작되었다. 첫 번째 변인은 틀로, 네모틀 조건과 탈네모틀 조건으로 구분된다. 두 번째 변인은 획으로, 세리프 조건과 산세리프 조건으로 구분된다. 실험 1 에서의 예측은 다음과 같다. 첫째, 선행 연구와 같이 네모틀 글자체가 읽기 수행을 촉진시킨다면, 탈네모틀 글자 체보다 네모틀 글자체에서 유의미하게 더 빠른 읽기 속도가 나타날 것이다. 둘째, 컴퓨터 환경에서 세리프 요소가 노이 즈로 작용한다면 세리프 조건보다 산세리프 조건에서 유의 미하게 더 빠른 읽기 속도가 나타날 것이다. 셋째, 탈네모틀 글자체일 때 획의 영향을 더 크게 받는다면, 틀 조건과 획 
조건 간의 상호작용 효과가 관찰될 것이다.

\subsubsection{Participants}

이화여자대학교 재학생 23명이 실험에 참가하였다. 참가 자들의 평균 연령은 23세(21 30세, $S D=2.15)$ 였으며, 평 균 시력은 $1.14(0.8 \sim 1.2, S D=0.12)$ 로 정상 시력 또는 교 정 후 정상 시력이었다. 모든 참가자는 한국어를 모국어로 사용하였다.

\subsubsection{Apparatus}

실험 절차는 E-Prime(Ver. 2.0) 실험용 프로그램으로 제 어되었다. 자극은 컴퓨터에 연결된 19인치 평면 모니터에 제시되었다. 실험 자극은 흰 바탕에 검은 색으로 모니터 중 앙에 제시되었으며, 참가자와 모니터 간 거리는 $1 \mathrm{~m}$ 로 유지 되었다. 실험자가 참가자의 반응을 기록할 수 있도록 추가 모니터와 키보드를 설치하였다.

\subsubsection{Materials and design}

Song과 Lee(2010)에서 쓰인 중학교 1학년 국어 교과서 발췌 문장 200개를 실험 자극으로 사용하였다. 한 문장은 10 개 어절로 구성되었으며, 띄어쓰기를 포함하여 글자 수는 평균 38 개, 어절을 이루는 음절 수는 2 4개였다.

글자체는 네모틀 글자체 중 세리프체로 바탕체, 산세리프 체로 굴림체, 탈네모틀 글자체 중 세리프체로 휴먼아미체, 산세리프체로 휴먼샘체를 선정하였다. 글자체 선정은 컴퓨터 기본 글꼴에 포함되어 있는 고빈도 사용 글자체를 기준으로 하였다(Table 1). 바탕체는 인쇄 매체에서 가장 많이 사용 되고, 굴림체는 정보 제공 서비스에 주력하는 검색포탈과 언 론사 사이트에서 본문용 글자체로 사용되고 있다. 탈네모틀 글자체의 경우, 컴퓨터 환경과 인쇄 매체 모두에서 고빈도로 사용되지 않기 때문에 비교적 사용 빈도가 높아 친숙한 글자 체를 선정하였다(Kim and Park, 2008; Yu, 2006).

Table 1. Fonts used in the experiments

\begin{tabular}{c|c|c}
\hline & 네모틀 & 탈네모틀 \\
\hline 세리프 & 바탕체 & 휴먼아미체 \\
\hline 산세리프 & 굴림체 & 유먼샘체 \\
\hline
\end{tabular}

글자 크기로는 인터넷에서 가장 많이 사용되는 $\mathrm{HTML}$ $\mathrm{H} 3$ 를 채택하였다. H3는 일상적인 보는 거리 $(50 \mathrm{~cm})$ 에서 시 각도로 0.52 도에 해당하는 크기이다. 본 연구에서는 보는 거 리 $1 \mathrm{~m}$ 에서 굴림체 글자 크기 14 포인트로 구현되었다. 글자 높이를 기준으로 각 글자의 크기를 조정한 선행 연구와 같이,
굴림체 글자 높이를 기준으로 바탕체, 굴림체, 휴먼아미체는 14 포인트, 휴먼샘체는 15포인트로 조정하였다(Arditi and Cho, 2005; Jung et al., 1993; Lee et al., 1993; Morris et al., 2002). 탈네모틀 글자체의 글자 높이는 받침이 있는 글 자를 기준으로 하였다.

글자체에 따라 4 개 블록으로 나누고 각 블록에서 25회 시행씩, 총 100 회의 시행을 실시하였다. 블록의 순서와 블록 내 시행은 참가자마다 무선화 하였다. 본 실험은 2(틀 조건: 네모틀 · 탈네모틀 $) \times 2$ (획 조건: 세리프 · 산세리프) 완전 반복 설계로서 모든 변인은 참가자 내 변인으로 조작되었다.

\subsubsection{Procedure}

개별적으로 정한 시간에 한 명씩 실험을 진행하였다. 참가 자가 실험실에 오면 먼저 간단한 시력검사를 실시한 후, 실 험 절차에 대한 지시문을 읽게 하였다. 그 후, 12회(4개 글 자체 조건당 세 문장)의 연습 시행과 4 개 글자체 조건 블록 의 본 실험으로 구성된 읽기 과제를 수행하게 하였다.

한 시행의 순서는 다음과 같다(Figure 3). 먼저 모니터 화 면에 <준비가 되었으면 마우스를 눌러 주십시오.>라는 메시 지를 제시하였다. 참가자가 마우스를 누르면 화면 중앙에 응 시점 $("+++")$ 을 $500 \mathrm{~ms}$ 동안 제시하고, 이후에 각 글자체 와 글자 크기가 적용된 문장을 한 줄로 제시하였다. 참가자 들의 과제는 가능한 한 빠르고 정확하게 문장을 소리 내어 읽는 것이었다. 참가자가 한 문장의 읽기를 끝내면 실험자는 엔터키를 눌렀고, 빈 화면이 제시되었다. 참가자가 잘못 읽 은 어절 수를 실험자가 입력하면, 그 다음 시행을 위한 준비 화면이 제시되며 다음 시행이 동일하게 진행되었다. 한 실험 의 총 소요 시간은 20 분이었다.

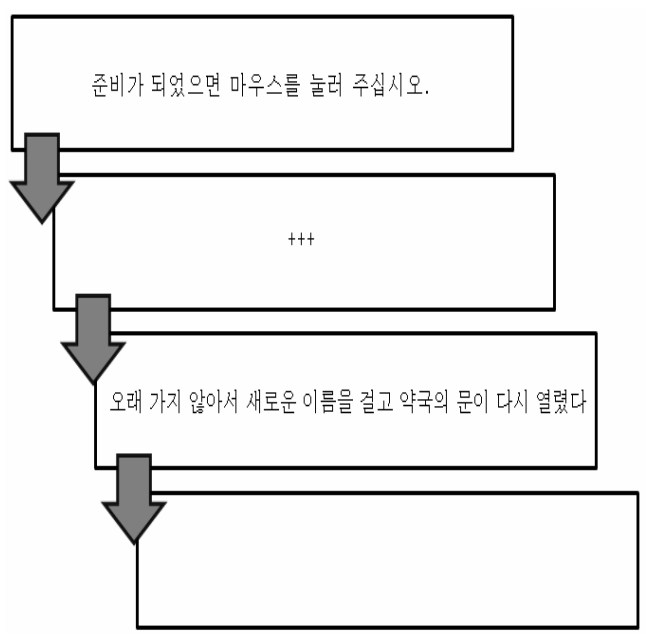

Figure 3. Experimental procedure 


\subsection{Experiment 2}

실험 1 에서는 네모틀 글자체와 탈네모틀 글자체 간 글자 크기를 받침 있는 글자를 기준으로 유사하게 맞추었다. 그러 나 탈네모틀 글자체의 특성상 몇 가지 물리적 속성에서 네모 틀 글자체와 차이가 존재했다. 첫째, 탈네모틀 글자체에서는 받침이 있는 글자에 비해 받침이 없는 글자에서 높이가 약 $1 / 2$ 줄어든다. 둘째, 탈네모틀 글자체에서는 같은 크기의 네 모틀 글자체에 비해 장평이 줄어든다. 셋째, 네모틀 글자체 보다 탈네모틀 글자체에서 글자 간 간격과 단어 간 간격이 좁게 나타난다. 글자 크기 및 간격이 읽기 과정에 중요한 영 향을 미친다는 연구 결과들이 보고되고 있다(Chung, 2002; Legge et al., 2007; Rayner et al., 1998). 그렇다면 실험 1 에서 관찰된 탈네모틀 글자체에서의 읽기 속도 저하는 글 자체의 틀 뿐만 아니라 크기, 장평, 자간, 어간 등의 물리적 속성에 기인했을 가능성이 있다.

실험 2에서는 틀 외의 다른 물리적 속성이 네모틀 글자체 와 탈네모틀 글자체 간의 읽기 속도 차이를 발생시켰을 가능 성을 배제하고자 하였다. 이를 위해 탈네모틀 글자체와 네모 틀 글자체 간 글자 높이뿐 아니라 글자 유형에 따른 크기, 장평, 자간, 어간을 통제하였다. 실험 1 에서 나타난 결과가 글자체 간 다른 물리적인 속성에서의 차이보다 틀의 효과 때 문이었다면 이러한 차이를 최소화하였을 때에도 탈네모틀 글자체보다 네모틀 글자체에서 유의미하게 더 빠른 읽기 속 도가 나타날 것이다.

\subsubsection{Participants}

실험 1에 참가하지 않은 이화여자대학교 재학생 23명이 실험에 참가하였다. 참가자들의 조건은 실험 1 과 동일하였다. 참가자들의 평균 연령은 23세(20 27세, $S D=2.10$ )였으며, 평균 시력은 $1.14(0.8 \sim 1.2, S D=0.11)$ 로 정상 시력 또는 교정 후 정상 시력이었다.

\subsubsection{Apparatus}

실험 1 과 동일한 기구가 사용되었다. 실험 1 과 달리, 실험 2 에서는 참가자와 모니터 간 거리를 $88 \mathrm{~cm}$ 로 유지하였다. 실험 1 과 보는 거리가 다른 이유는 변경된 글자체와 글자 크기를 기준으로 실험 1 과 동일한 0.52 도 시각도를 맞추기 위해 참가자와 모니터 간 거리를 조정하였기 때문이다.

\subsubsection{Materials and design}

실험 1 과 동일한 문장 자극과 설계를 사용하였다. 각 조건 의 글자체도 동일하였으나, 글자체 간 물리적인 속성 차이를 최소화하기 위해 Font Creator 5.0을 사용하여 탈네모틀 글 자체인 휴먼아미체와 휴먼샘체의 장평, 자간, 어간을 변형시
켰다. 먼저, 네모틀 글자체인 굴림체와 바탕체의 글자 높이 평균값에 탈네모틀 글자체의 '가'형과 '각'형 평균값을 일치 시켰다. 그 다음 네모틀 글자체의 평균 장평을 기준으로 탈 네모틀 글자체의 '가'형, '고'형, '과'형 평균값을 일치시켰다. 마지막으로 네모틀 글자체와 탈네모틀 글자체의 자간 및 어 간이 유사하도록 조절하여, 전체 문장 길이도 유사하게 일치 시켰다. 실험 1 과 동일하게 문장은 모니터 화면에 한 줄로 제시하였다. 또한 상용 글자 크기를 유지하기 위해 굴림체 0.52 도를 기준으로 굴림체, 바탕체는 11 포인트, 휴먼아미체 는 14포인트, 휴먼샘체는 15포인트로 조정하였다(Figure 4). 이처럼 실험 2에서는 변형 탈네모틀 글자체를 생성하여 탈네모틀과 네모틀 글자체의 글자 크기, 장평, 자간, 어간 차 이를 수치적으로 최소화하고, 읽기 수행에서 글자체의 틀과 획의 효과만을 살펴보고자 하였다.

설계는 실험 1 과 동일하였다.

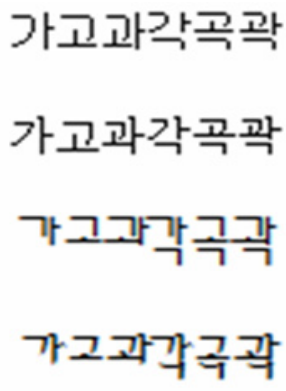

Figure 4. Transformed fonts in the experiment 2

\subsubsection{Procedure}

실험 절차는 실험 1 과 동일하였다.

\section{Results}

\subsection{Experiment 1}

실험 1 에서는 실험 참가자 23명을 대상으로 결과를 분석 하였다. 읽기 속도(words per minute: wpm)는 1 분당 정 확하게 읽은 어절 수로 계산하였다. 즉, 해당 문장을 읽는 데 걸린 시간을 정확하게 읽은 어절 수로 나눈 다음 1 분 단위로 환산하여 계산하였다.

읽기 속도에 대해 틀과 획을 참가자 내 변인으로 하여, 2 (틀) $\times 2$ (획) 반복측정 분산분석 $(\mathrm{ANOVA})$ 을 실시한 결 과(Figure 5), 네모틀일 때 읽기 속도가 증가하는 틀 주효 과가 나타났고 $[F(1,22)=6.43, M S E=18.85, p<.05]$, 
획 주효과는 유의미하지 않았다 $[F(1,22)=1.94, M S E=$ $8.64, p=.18]$. 두 조건 간의 상호작용 역시 유의미하지 않 은 것으로 나타났다 $[F(1,22)=.03, M S E=8.80, p=.86]$.

탈네모틀 글자체보다 네모틀 글자체에서 읽기 속도가 더 증가하였고(123.83wpm 대 $126.13 \mathrm{wpm})$, 세리프체와 산 세리프체 간에는 유의미한 차이가 없었다 $(124.55 \mathrm{wpm}$ 대 $125.41 \mathrm{wpm})$. 실험 1 의 결과를 통해 글자체의 틀과 획 중 에서 틀이 한글 읽기 수행에 영향을 미친다는 것을 확인하 였다.

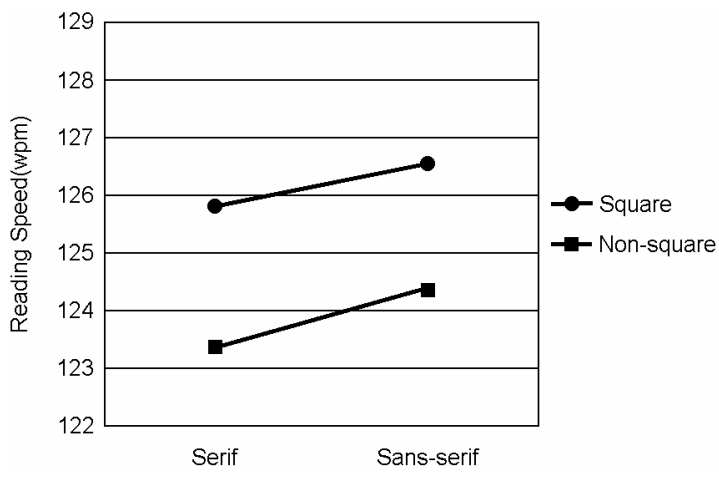

Figure 5. Reading speed as a function of font conditions in the experiment 1

\subsection{Experiment 2}

실험 2에서는 실험 참가자 23명을 대상으로 결과를 분석 하였다. 읽기 속도에 대해 틀과 획을 참가자 내 변인으로 하 여, 2 (틀) $\times 2$ (획) 반복측정 분산분석을 실시하였다(Figure 6). 그 결과, 네모틀일 때 읽기 속도가 증가하는 틀 주효과 가 나타났고 $[F(1,22)=16.74, M S E=7.88, p<.001]$, 획 주효과는 유의미하지 않았다 $[F(1,22)=.07, M S E=$ $12.95, p=.80]$. 두 조건 간의 상호작용 역시 유의미하지 않은 것으로 나타났다 $[F(1,22)=1.30, M S E=4.92, p$ $=.27]$.

탈네모틀 글자체보다 네모틀 글자체에서 읽기 속도가 더 증가하였다(125.40wpm 대 $127.79 \mathrm{wpm})$. 세리프체와 산 세리프체 간에는 유의미한 차이가 없었다 $(126.50 \mathrm{wpm}$ 대 $126.69 \mathrm{wpm})$. 네모틀 글자체와 탈네모틀 글자체 간 틀 외 에 다른 물리적 속성 (크기, 장평, 자간, 어간)에서의 차이를 최소화하여도 틀이 한글 읽기 수행에 영향을 미친다는 실험 1 의 결과를 반복 확인할 수 있었다.

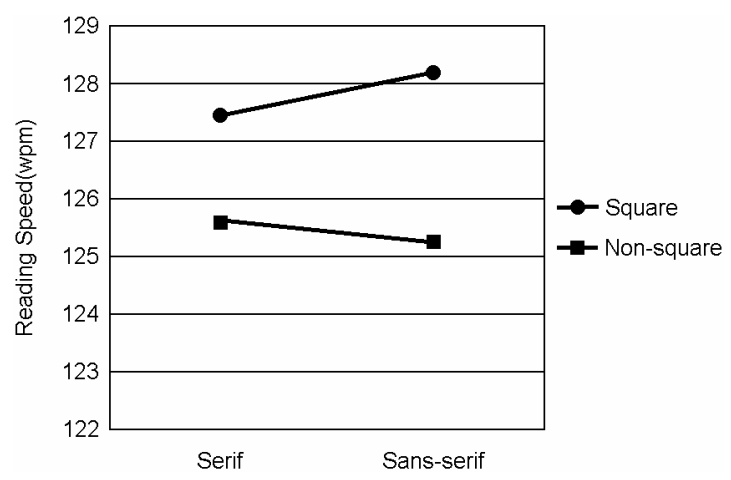

Figure 6. Reading speed as a function of font conditions in the experiment 2

\section{Discussion}

본 연구에서는 한글 글자체의 틀 요소와 획 요소가 읽기 속도에 미치는 영향을 살펴보았다. 본 연구의 결과는 다음과 같다. 첫째, 탈네모틀 글자체보다 네모틀 글자체에서 읽기 속도가 더 빠르게 나타났다. 이는 네모틀 글자체와 탈네모틀 글자체 간 물리적인 속성을 최소화하여도 동일하게 나타났 다. 둘째, 세리프체와 산세리프체 간에는 읽기 속도가 유사 하게 나타났다. 셋째, 글자체의 틀에 따라 획의 효과는 다르 게 나타나지 않았다.

실험 1,2 의 결과, 국내 선행 연구 결과와 동일하게 네모 틀 글자체인 굴림체와 바탕체에서 읽기 속도가 향상되었다. 즉, 컴퓨터 환경에서 네모틀 글자체에서의 수행이 더 우월한 것으로 나타났다. 실험 2에서 탈네모틀 글자체의 물리적인 속성을 네모틀 글자체와 더 유사하게 통제하여도 동일한 틀 효과가 나타난 것은, 이 효과가 글자의 물리적인 속성 때문 이 아니라 틀의 모양 때문이라는 것을 시사한다.

네모틀 글자체와 달리 탈네모틀 글자체에서는 글자 유형 에 따라 글자의 형태가 달라지기 때문에 읽기 속도가 저하 될 수 있다. 영어권 연구에서는 첫 글자만 대문자로 제시되 고 소문자로 이루어진 일반적인 문장보다 알파벳 대문자와 소문자가 혼합되어 제시된 문장(예: AlTeRnAtInG)에서 표 적 단어에 대한 응시 시간이 증가하였으며, 명명 과제에서도 대소문자 혼합 제시 조건에서 수행률이 감소하였다(Juhasz et al., 2006). 제시 형태의 지속적인 변이가 단어 재인을 방 해하여 어휘 처리를 어렵게 하기 때문이다(Herdman et al., 1999). 대소문자 혼합 제시에서 글자 형태의 변이가 나타나 듯이, 탈네모틀 글자체에서도 받침이 없는 '가', '고', '과' 유 형 글자의 경우 받침이 있는 '각', '곡', '곽' 유형 글자의 $1 / 2$ 로 
높이가 줄어든다. 이로 인한 형태의 변이가 단어 재인을 방 해하는 요소로 작용하여 탈네모틀 글자체에서의 읽기 속도 가 저하되었을 수 있다.

네모틀 글자체에서 탈네모틀 글자체에 비해 자모 위치가 잘 변별되었을 가능성도 존재한다. 한글은 자모 수준에서 순 차 처리되기보다 글자 또는 음절 단위로 병렬 처리되기 때문 에(Jung et al., 1993; Park, 2006), 첫 자음과 받침 자음 변 별에 도움을 주는 단서가 필요하다. 네모틀 글자체에서는 같 은 'ㄱ'이라도 첫 자음에 위치할 때는 아래 획이 왼쪽으로 꺾 인 형태를 취하지만, 받침 자음에 위치할 때는 직선 형태를 취한다. 따라서 자모 모양이 자모 위치를 변별하는 데 도움 을 준다. 반면, 탈네모틀 글자체에서는 자모 모양이 항상 일 정하거나 변화가 적기 때문에 자모 위치를 인식하게 하는 단서가 부족하다. 자모의 위치를 변별하기 어려울수록 한 글 자를 읽기 위한 시간이 증가하게 되고, 결과적으로 읽기 속 도가 저하될 수 있다.

영어권 연구 결과와 달리, 한글에서는 획의 특성이 읽기 수행에 영향을 미치지 않았다. 한글에서는 모아쓰기로 인해 인접 자모가 측면뿐 아니라 위나 아래에 제시되어 영어에 비 해 획의 장식 요소가 읽기를 더 크게 방해할 수 있다. 그럼 에도 불구하고 획의 영향이 나타나지 않은 것은 본 연구에 서 사용된 상용 글자 크기가 해상도의 영향을 받지 않을 만 큼 충분히 컸기 때문으로 보인다. 세리프체에서 더 느린 읽 기 속도를 관찰한 Moret-Tatay와 Perea(2011)도 본 연 구와 동일한 14 포인트의 글자 크기를 사용하였다. 그러나 같은 14 포인트라도 알파벳 소문자가 한글에 비해 $1 / 2$ 크기 로 표현되기 때문에 획의 영향을 상대적으로 크게 받았을 수 있다. 글자 크기가 작을수록 컴퓨터에서의 해상도 한계로 세리프체의 장식 또는 획이 번져 보이거나 겹쳐 보이기 때문 이다(Josephson, 2008; Moret-Tatay and Perea, 2011; Morris et al., 2002). 이 경우 각 철자가 불명확하게 보임 으로써 철자 식별이 저하되고, 철자 간 경계가 모호하여 철 자 간 측면 차폐, 즉, 밀집 효과(crowding effect)가 증가할 수도 있다(Bouma, 1970). 따라서 본 연구에서 사용된 상용 글자 크기보다 더 작은 글자 크기로 한글 읽기 과제를 제시 한다면 한글에서도 세리프체에서의 읽기 속도가 저하될 수 도 있다.

한글 읽기 수행에서 획의 영향이 나타나지 않은 또 다른 원인으로 글자 단위의 체제화를 생각해볼 수 있다. 모아쓰기 라는 한글의 표기 특성상 글자 단위의 체제화가 잘 이루어지 면 글자 재인이 촉진될 수 있다(Park, 2006). 한글 세리프 체에서 나타나는 획의 꺾임과 굵기 변화는 글자의 경계에 대한 정보를 준다. 예를 들어 '각'의 경우, 중심에서 경계로 갈수록 획의 굵기가 가늘어질 뿐 아니라, 모음 윗부분에서의 꺾임이 글자의 가장자리에 대한 정보를 제공한다. 이로 인해
산세리프체에 비해 세리프체에서 글자 간 경계가 명확해져 글자 단위의 체제화가 더 잘 되었을 가능성이 있다. 그러나 세리프체에서는 장식요소의 방해도 함께 작용하기 때문에, 체제화에서의 용이성으로 인한 글자 재인에서의 이득이 상 쇄되어, 결과적으로 산세리프체에서의 수행과 큰 차이가 나 지 않았을 수 있다.

읽기 수행에서 획의 영향이 드러나지 않은 것은 한국어 독 자들이 두 글자체에 모두 친숙하기 때문일 수도 있다. 영어 권 읽기 연구에서는 독자들이 친숙한 Times New Roman 글자체에서 덜 친숙한 Harrington이나 Script MT 글자체 에 비해 전체 읽기 시간, 응시(fixation) 횟수, 응시 시간 면 에서 우월한 수행을 보였다(Slattery and Rayner, 2010). 우리나라의 경우 인쇄 매체에서는 세리프체(명조체, 바탕체), 인터넷 상에서는 산세리프체(굴림체, 돋움체)가 많이 사용된 다. 두 가지 매체를 동시에 사용하는 사람들이 증가하면서 세리프체와 산세리프체에 모두 친숙하게 되어, 어느 글자체 로 자극이 주어지든 읽기 수행에 큰 영향을 받지 않았을 수 있다.

본 연구는 주로 세리프 유무에 초점을 맞춰온 서양의 연구 와 네모틀 및 탈네모틀에 초점을 맞춰온 국내 연구에 기반하 여 두 변인을 모두 적용한 최초의 한글 글자체 실험 연구이 다. 최근 증가한 컴퓨터 읽기 환경에서 상용 글자체와 글자 크기를 기준으로 하였다는 점에서 현실적인 의미를 갖는다. 본 연구 결과에 따르면 현재 인터넷에서 상용되고 있는 굴림 체는 비교적 적합한 읽기 환경을 제공하고 있다. 그러나 최 근 글자체 개발은 탈네모틀 글자체를 중심으로 이루어지고 있는데, 가독성을 고려한다면 네모틀 글자체를 중심으로 개 발 방향을 바꾸어야 할 필요성이 제기된다.

\section{Conclusion}

본 연구에서는 컴퓨터 환경에서 글자체의 틀과 획 요소가 한글 문장의 읽기 속도에 미치는 영향을 검증하였다. 틀로는 네모틀 조건과 탈네모틀 조건, 획으로는 세리프 조건과 산세 리프 조건을 비교하였다. 실험 1에서 탈네모틀 조건에 비해 네모틀 조건에서 읽기 속도가 더 빠르게 나타났고, 획의 영 향은 유의하지 않았다. 틀과 획의 상호작용은 없었다. 실험 2에서는 글자체 조건 간 글자 크기, 장평, 자간, 어간을 유사 하게 통제하여 틀과 획의 효과를 재검증하였다. 실험 1 의 결 과와 일치하게, 실험 2에서도 네모틀 조건이 탈네모틀 조건 에 비해 더 빠른 읽기 속도를 보였으며, 획에 따른 읽기 속 도 차이는 보이지 않았다. 틀과 획의 상호작용 역시 없었다. 본 연구를 통해 컴퓨터 환경의 한글 읽기 수행에서 글자체의 
틀이 중요한 영향을 미칠 수 있음을 확인하였다. 탈네모틀에 비해 네모틀 글자체의 우위는 한글표기의 시지각적 특성과 연관시켜 설명할 수 있다. 컴퓨터 환경에서 네모틀 글자체가 보다 효율적인 한글 정보 처리를 유도할 수 있음을 본 연구 결과는 시사하고 있다.

\section{Acknowledgements}

This work was supported by the National Research Foundation of Korea Grant funded by the Korean Government(NRF-2010330-B00209).

\section{References}

Akhmadeeva, L., Tukhvatullin, I. and Veytsman, B., Do serifs help in comprehension of printed text? An experiment with cyrillic readers, Vision Research, 65, 21-24, 2012

Arditi, A. and Cho, J., Serifs and font legibility, Vision Research, 45(23), 2926-2933, 2005

Bouma, H., Interaction effects in parafoveal letter recognition, Nature, 226(5241), 177-178, 1970

Choi, Y.-S. and Yoon, J., A study on legible typography for monitor by analysis of cognitive science, Basic Design and Art Research, 8(3), 571-579, 2007.

Chung, S.T.L., The effect of letter spacing on reading speed in central and peripheral vision, Investigative Ophthalmology and Visual Science, 43(4), 1270-1276, 2002.

Herdman, C.M., Chernecki, D. and Norris, D., Naming case alternated words, Memory and Cognition, 27(2), 254-266, 1999.

Josephson, S., Keeping your readers' eyes on the screen: An eye-tracking study comparing sans serif and serif typefaces, Visual Communication Quarterly, 15(1), 67-79, 2008.

Juhasz, B.J., Liversedge, S.P., White, S.J. and Rayner, K., Binocular coordination of the eyes during reading: Word frequency and case alternation affect fixation duration but not fixation disparity, The Quarterly Journal of Experimental Psychology, 59(9), 1614-1625, 2006.

Jung, W.H., Han, J.J. and Chung, C.S., "The effects of Hangul letter form on readability", Proceedings of the 5th Conference on Human and Cognitive Language Technology, 10(pp. 207-216), Korea. 1993.

Kim, H.-Y. and Cheong, C.-S., The effect of MEUNGZO and SAEMMUL fonts on HANGUL recognition, The Korean Journal of Experimental and Cognitive Psychology, 4(1), 25-35, 1992.

Kim, M. and Kim, J., A study on module for digital font from Hangeul calligraphy, Basic Design and Art Research, 6(1), 121-131, 2005.
Kim, Y.-K. and Park, S.-H., Space structure character of Hangeul typography, Journal of Korea Contents Association, 8(3), 86-95, 2008

Lee, S.J., Jung, W.H. and Chung, C.S., "The factors in reading Hangul text: Font, width-to-height ratio of a letter, line length", Proceedings of the 5th Conference on Human and Cognitive Language Technology, 10 (pp. 193-205), Korea. 1993.

Legge, G.E. and Bigelow, C.A., Does print size matter for reading? A review of findings from vision science and typography, Journal of Vision, 11(5), 1-22, 2011.

Legge, G.E., Rubin, G.S. and Luebker, A., Psychophysics of reading. V. The role of contrast in normal vision, Vision Research, 27(7), 1165 $-1177,1987$.

Legge, G.E., Cheung, S.-H., Yu, D., Chung, S.T.L., Lee, H.-W. and Owens, D.P., The case for the visual span as a sensory bottleneck in reading, Journal of Vision, 7(2), 1-15, 2007.

MacKeben, M., Enhancement of peripheral letter recognition by typographic features, Visual Impairment Research, 2(2), 95-103, 2000.

Min, D.S., Changes of typeface for Hangul text in the digital age, Basic Design and Art Research, 12(2), 187-195, 2011.

Moret-Tatay, C. and Perea, M., Do serifs provide an advantage in the recognition of written words?, Journal of Cognitive Psychology, 23(5), 619-624, 2011

Morris, R.A., Aquilante, K., Bigelow, C. and Yager, D., "Serifs slow RSVP reading at very small sizes, but don't matter at larger sizes", Proceedings of the Society for information Display International Symposium Digest of Technical Papers, (pp. 244-267), Boston. MA. 2002.

Park, C.H., The influence of perceptual grouping of letters on the perception of Hangul syllable blocks: Using syllable usableness judgment task, The Korean Journal of Experimental Psychology, 18(3), 173-185, 2006.

Rayner, K., Fischer, M.H. and Pollatsek, A., Unspaced text interferes with both word identification and eye movement control, Vision Research, 38(8), 1129-1144, 1998.

Russell-Minda, E., Jutai, J.W., Strong, J.G., Campbell, K.A., Gold, D., Pretty, L. and Wilmot, L., The legibility of typefaces for readers with low vision: A research review, Journal of Visual Impairment and Blindness, 101(7), 402-415, 2007.

Slattery, T.J. and Rayner, K., The influence of text legibility on eye movements during reading, Applied Cognitive Psychology, 24(8), 1129-1148, 2010.

Smither, J.L. and Braun, C.C., Readability of prescription drug labels by older and younger adults, Journal of Clinical Psychology in Medical Settings, 1(2), 149-158, 1994

Song, Y. and Lee, H.-W., The context effects in reading Hangul in normal and low vision, Korean Journal of Cognitive Science, 21(2), 339-357, 2010.

Woods, R.J., Davis, K. and Scharff, L.F.V., Effects of typeface and font size on legibility for children, American Journal of Psychological Research, 1(1), 86-102, 2005.

Yager, D., Aquilante, K. and Plass, R., High and low luminance letters, acuity reserve, and font effects on reading speed, Vision Research, 
38(17), 2527-2531, 1998.

Yoo, J.S., A study on the change in the formative elements and the characteristics of typography of digital Dodum typeface in Hangul: Focus on traditional square typeface, Basic Design and Art Research, 11(1), 269-280, 2010

Yu, D., Cheung, S.-H., Legge, G.E. and Chung, S.T.L., Effect of letter spacing on visual span and reading speed, Journal of Vision, 7(2), $1-10,2007$.

Yu, J.-M., A historical study on the flexibility square-format typeface and the prospects: Focused on the three-pairs fonts of Hangeul, Journal of Korean Society of Design Science, 19(2), 241-250, 2006.

\section{Ko Eun Lee: lindes@naver.com}

Highest degree: M.A., Department of Psychology, Ewha Womans University

Position title: Ph.D. candidate, Department of Psychology, Ewha Womans University

Areas of interest: Visual and Perceptual Factors in Reading, Lexical Processing, Cognitive Aging

Hye-Won Lee: hwlee@ewha.ac.kr

Highest degree: Ph.D., Department of Psychology, University of Massachusetts, Amherst

Position title: Professor, Department of Psychology, Ewha Womans University

Areas of interest: Reading, Hangul Word Recognition, Visual Cognition

Date Received : 2013-04-12

Date Revised : 2013-07-08

Date Accepted : 2013-07-23

\section{Author listings}

Sunkyoung Kim: skkim357@gmail.com

Highest degree: B.A., Department of Psychology, Ewha Womans University

Position title: M.A. candidate, Department of Psychology, Ewha Womans University

Areas of interest: Visual and Perceptual Factors in Reading, Cognitive Aging 